\title{
The Past, Present, and Future of Rangeland Grasshopper Management
}

\author{
KERRI M. SKINNER
}

\begin{abstract}
Knowledge is power in protecting our crops against the ravages of a tiny insect, as in all other undertak ings; and according as accurate knowledge regarding this locust plague is disseminated among our people, will they be able to vanquish the common foe.-C.V. Riley, 1877
\end{abstract}

Grasshoppers have undoubtedly made large historical impacts on the rangelands of the United States through their reputedly voracious appetites and sheer numbers. Like other species whose habits conflict with human interests, efforts to understand the biology and ecology of grasshoppers have been driven by the quest for better ways to suppress their numbers. While there are good reasons for this approach to grasshopper research, it has not resulted in a thorough understanding of the biology, ecology, and population dynamics of these insect herbivores, nor the ability to accurately predict or prevent outbreaks.

While there are more than 600 species of grasshoppers in North America, only about a dozen grasshopper species frequently develop high densities on rangelands.

\section{Basic biology}

While there are more than 600 species of grasshoppers in North America, only about a dozen grasshopper species frequently develop high densities on rangelands. High numbers of grasshoppers are commonly called outbreaks or infestations. Rangeland grasshoppers lack the gregarious behavior of locusts, which is triggered by high population densities and results in migratory swarms. Immature stages, called nymphs, resemble miniature adults but lack mature wings and reproductive organs.

As herbivores, grasshoppers are infamous for their appetites, although their destructiveness may be as much due to clipping vegetation (without eating the severed portion) as to actually consuming it. The ecological functions of grasshoppers include important roles as litter producers, food sources for grassland birds and other wildlife, and weed control agents.

\section{A troubled history}

Grasshoppers and humans have been at cross purposes since the earliest days of agriculture. Most early records of grasshopper problems in America can be ascribed to one species: Melanoplus spretus (Walsh), the Rocky Mountain grasshopper or locust. Unlike other North American species, M. spretus periodically formed swarms which moved between permanent breeding grounds in the Rocky Mountain states and the fertile farmlands of the Mississippi valley. Six major swarms of this species, covering large regions of the Great Plains and lasting two or more years, were reported between 1818 and 1875. The "plague" of 1857 covered 12,000 square miles, over most of which "every green thing cultivated by man was consumed" (Riley 1877).

For reasons which remain largely unknown, the Rocky Mountain grasshopper is apparently extinct. Ironically, habitat loss, not pesticide use, was responsible for the extermination of the most pestiferous species encountered on western rangelands. Despite the disappearance of M. spretus, its effects on entomology in America were long-lasting. It is probable that grasshopper plagues drove a shift from grain farming to cattle ranching, influenced tillage practices, fostered turkey production, and led to increasing dependence of agriculture on subsidies and aid provided by the federal government.

In 1877, an act of Congress created the United States Entomological Commission in response to the plight of farmers caused by the widespread grasshopper plagues of the preceding years. The Commission, directed by Charles Valentine Riley, was charged with reporting on Rocky Mountain

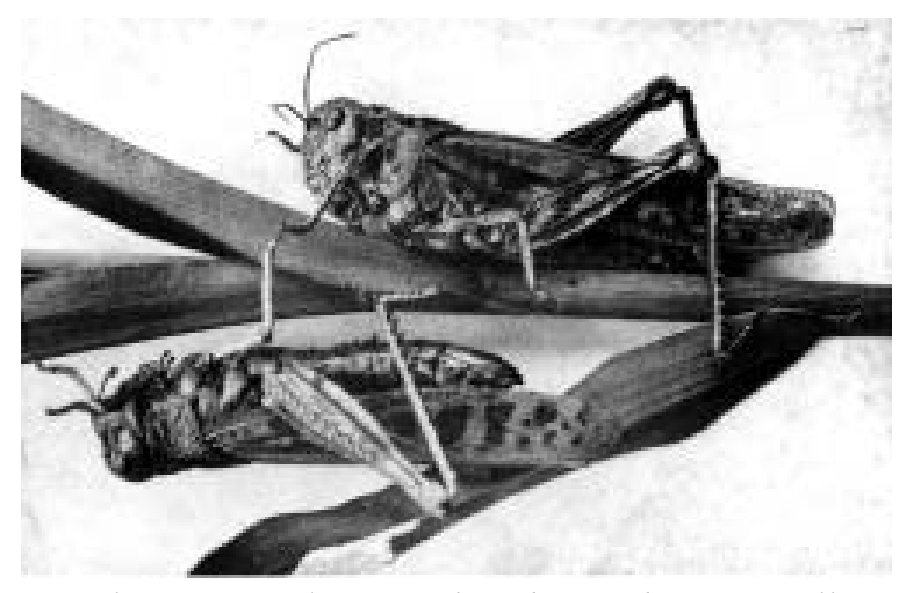

Rocky Mountain locusts. Photo by Jacoby's Art Gallery, Minnesota Historical Society. 
grasshopper infestations and "the best practicable method of preventing their recurrence or guarding against their invasions" (USEC 1878). This shift in the focus of federally funded entomology from a naturalistic approach to one concerned with injurious insects may be viewed as the origin of applied (economic) entomology in the United States.

\section{Dealing with infestations}

The Rocky Mountain locust probably swarmed over the Great Plains long before white settlers brought their wheat and cattle. Outbreaks would have provided an easily gathered source of nutrients for indigenous people. Large quantities could be collected during cold weather or by using fire to drive bands toward collection pits. Fire was later used by farmers to destroy grasshopper nymphs.

During the late nineteenth century, several methods were developed to help remove grasshoppers from agricultural lands. Preventive measures included conservation of game birds, crop rotation, irrigation, and planting the resistant crop sorghum. Means of destruction included collection with nets, plowing and harrowing to destroy eggs, and the use of turkeys and other domestic fowl. Various manifestations of the "hopperdozer," usually consisting of a pan of tar or coal oil mounted behind a horse or tractor, were used to collect very large numbers of wingless nymphs, a practice which was encouraged by bounties. Experiments involving chemicals, smudging and concussion were undertaken to find new methods to destroy eggs, nymphs and adults. By the 1930's, chemical control became "the most generally accepted method of grasshopper control in the United States" (Parker 1937). Mixtures of arsenic with bran or sawdust were recommended for poisoning nymphs and adults by ingestion. When new chemical insecticides, such as carbaryl and Malathion, became available, they were applied first as sprays and later in bran baits.

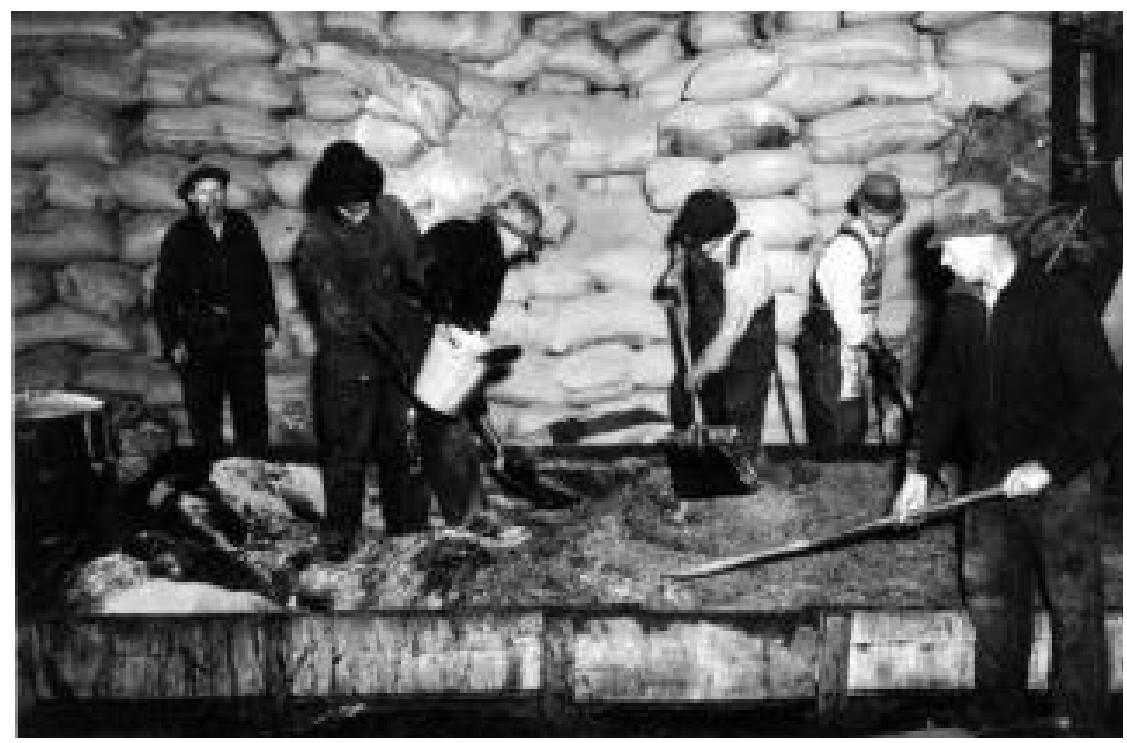

Mixing grasshopper bait, 1941. Photo by T.L. Aamodt, Minnesota Historical Society.
Methods for controlling grasshopper or locust infestations.

\begin{tabular}{ll}
\hline Past & Present \\
\hline Fire & Chemical sprays \\
Arsenic bait & Pesticide bait \\
Conservation of natural enemies (birds) & Nosema locustae bait \\
Nets and "hopperdozers" & Grazing management \\
Irrigation (drowning) & \\
Tillage (on cropland) & \\
\hline
\end{tabular}

Concerns over the use of toxic pesticides in agriculture drove the development of biological means to reduce insect pests, including grasshoppers. The most well-known biological control agent for grasshoppers is the pathogen Nosema lo custae Canning. Extensive research and field testing were done to investigate the feasibility of using $N$. locustae as a long-term solution for grasshopper outbreaks. This pathogen is now available commercially but its use and success in the field have been limited.

Until the 1950's, the concern was to protect crops, not rangeland, from grasshopper damage. Devastating plagues lead to a shift from farming to ranching and the advent of federal funding for rangeland grasshopper control. Management of grasshoppers on rangelands is different than on crop lands because the cost-benefit ratio differs. The cost of a control measure on rangeland often cannot be justified given the low value of forage; other options, such as selling off livestock or buying hay, may be more economical alternatives.

\section{The scientific approach}

The focus of federal grasshopper management programs has remained relatively unchanged for the last 120 years. From the start, entomologists have looked for practical ways to prevent grasshopper damage and control populations. The geographic distribution, life cycles, behavior and diets of pest species have been described in detail, in an effort to provide the knowledge that Riley (1877) believed would vanquish the foe. Early researchers noted relationships between grasshopper abundance and various environmental factors, including weather, fire, and earthquakes.

Interest in predicting grasshopper population levels and preparing for outbreaks, dates to the earliest days of grasshopper research. The second report of the U.S. Entomological Commission (USEC 1880) proposed the establishment of "a permanent system of [locust] observations and warnings" and daily bulletins to publish information on swarms. In the third report, the forecast for the coming summer was based on the "widely scattered" infestations of the previous year (USEC 1883). A similar approach has been used since the 1930's: Grasshopper surveys are taken annually for many western states and hazard maps are drawn, based on the field observations, to estimate grasshopper densities for the coming season. 


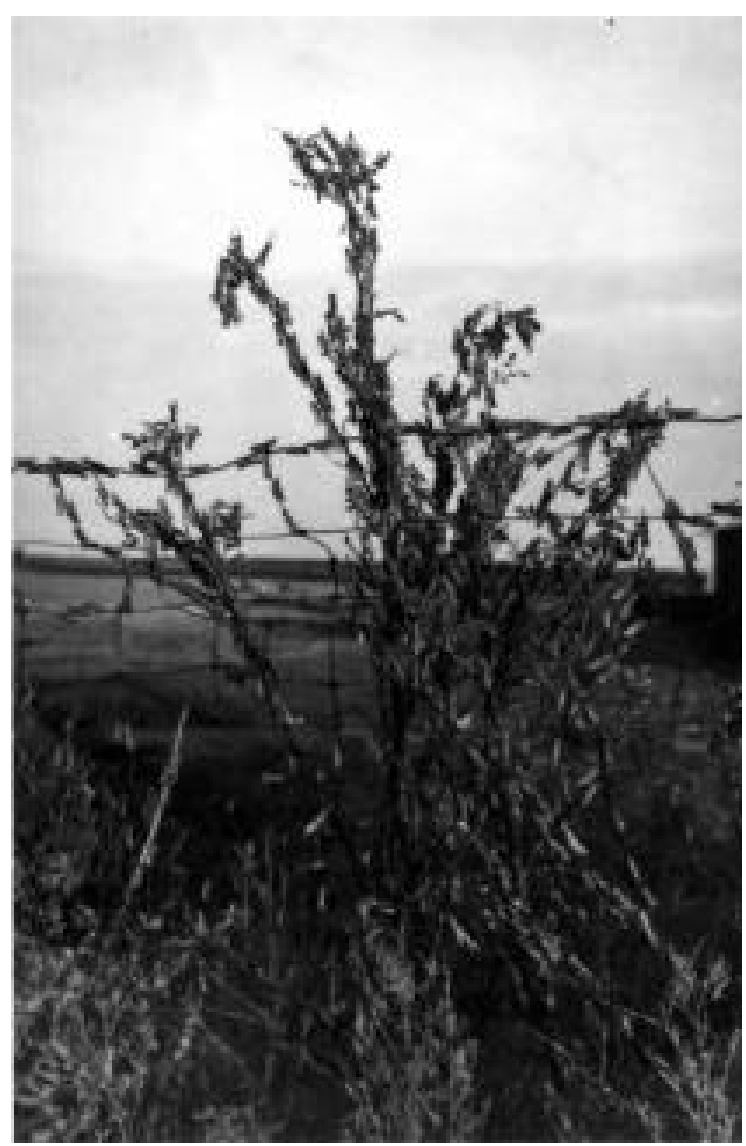

Grasshoppers waiting for the temperature to rise at Marshall, Minnesota. Minnesota Historical Society.

In the late 1980's, new techniques and computing power helped fortify efforts to predict and prepare for high grasshopper numbers. A computer simulation model called HOPPER was developed to improve decision-making when selecting between grasshopper treatment options. Research also was conducted on grasshopper community ecology and competition.

\section{Difficulties}

Despite more than 120 years of study on rangeland grasshopper ecology and population dynamics, we are still unable to accurately predict when or where the next grasshopper outbreak will occur. There are a number of reasons why outbreak prediction is difficult. First, the grasshopper species complex is composed of multiple species, each with particular habitat requirements, behaviors, adaptations, vulnerabilities and reproductive capacities. Under any given set of environmental conditions, there is likely to be at least one species in the community which can respond independently to those conditions and increase in abundance.

Irrespective of this heterogeneity, grasshopper communities are often treated as if composed of a single species. For example, control efforts frequently use a single treatment to manage all species, with varying success. Similarly, efforts to model grasshopper biology, ecology, or dynamics must focus either on a single species for which adequate information is available or on a generalized grasshopper model. Modeling a single species is insufficient for predicting the dynamics of the entire community, and modeling a generalized grasshopper is unlikely to accurately predict the dynamics of any "real" species. In addition, information gained from laboratory studies may not be applicable under field conditions and practical difficulties in measuring parameters such as egg mortality hamper modeling efforts.

Another complicating factor is that grasshopper populations fluctuate largely over both space and time. Many studies of grasshopper populations have ignored change over either time or space. While recent studies have recognized these complexities, most have focused on patterns in abundance during outbreak years and none have yielded complete understanding of the factors governing grasshopper population ecology.

In addition to predictive modeling efforts, survey and monitoring programs may be used to assess the potential for economically damaging grasshopper densities. The sampling schemes for these programs should be carefully designed such that the spatial and temporal frequency of samples matches the scale of patterning in the phenomenon of interest. In Colorado, the monitoring scheme is inadequate for detecting incipient grasshopper outbreaks because the average distance between sampled points is an order of magnitude larger than the size of local infestations.

\section{The future}

How can these obstacles be overcome? Riley may have been correct in stating that accurate knowledge is the key to living comfortably with grasshoppers in agricultural settings. However, vital information is still missing. Basic biological and ecological information is unavailable for many species. In addition, the relative impacts of environmental and biological factors on population growth have been speculated but are largely unknown. It is probable that the factors which are most important to grasshopper population dynamics will differ from one area of the Great Plains to another. Elucidating the factors which are most closely linked with increases in grasshopper abundance, and incorporating those variables into population models, may be the key to accurately predicting outbreaks.

\section{A new paradigm}

It is surprising that so much remains to be learned about a group of insects which have been so important in American agricultural history. This may be the legacy of an outlook which fails to recognize the heterogeneity of the grasshopper complex. Representative of this mentality is the fact that the disappearance of Melanoplus spretus, one of the West's most serious pests, has been overlooked even by historians: Schlebecker (1953) states that while conversion of the Great Plains to agriculture has decimated bison, wolves, beavers, and Native Americans, grasshopper communities remain largely unchanged. 
If progress is to be made in the study of grasshopper population dynamics, a new paradigm must be adopted. To date, research on grasshoppers has been structured by the traditional, hierarchical levels of biological organization: organism, population, community, ecosystem,

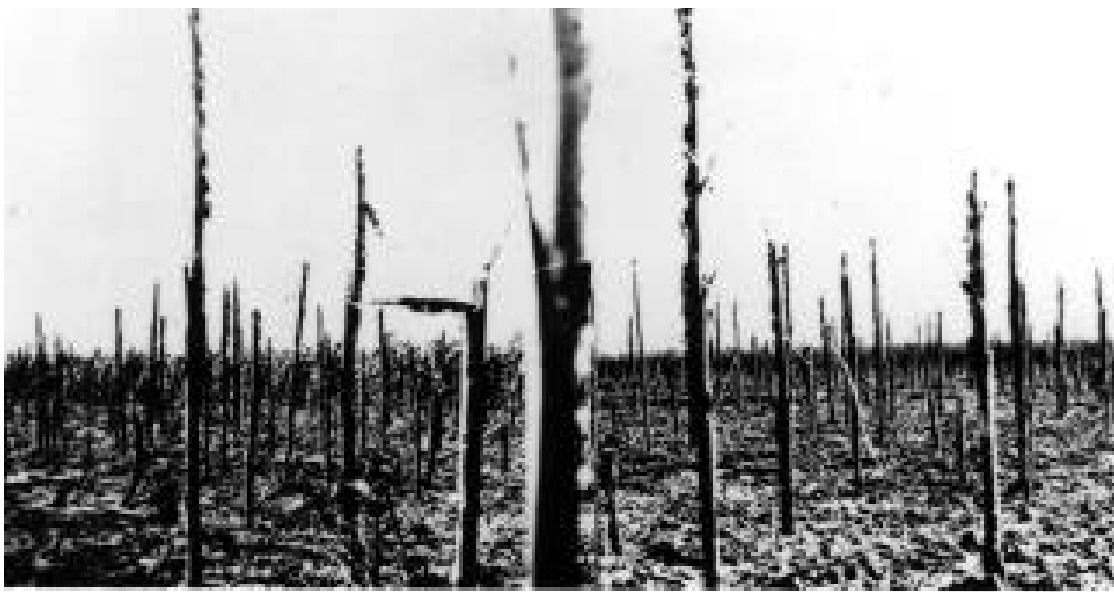

Grasshopper infestation in South Dakota. Minnesota Historical Society. tent of egg-deposits; the time of hatching of the young locusts; their movements both on foot and on wing" (USEC 1880, p. 318). The information was to be disseminated by the local press and updated daily during severe outbreaks.

The devastation caused by the Rocky Mountain biome. A shift to using scale-defined levels of organization would help to clarify the processes which provide the context for changes in abundance. In addition, the recognition and use of scale would direct research and management efforts toward the most appropriate levels for study and monitoring.

A spatial model of grasshopper dynamics is likely to be intricate. Grasshopper populations in Colorado are structured at more than one spatial scale, implying the influence of at least two classes of processes in structuring densities over space. Biotic factors may be dominant in producing spatial patterns at local scales, through plant community composition, competition, predation and parasitism. Abiotic habitat characteristics such as slope, aspect, and soil properties may be influential in selection of microhabitat but less important to population change.

Viewing rangeland grasshopper communities from a scale orientation would be beneficial to managers by determining the proper scale for survey, monitoring, and control efforts. Grasshopper densities are managed on multiple spatial scales. The field scale is managed by the individual landowner or lessee; if the land is publicly owned, then state and federal interests may also be involved in monitoring and treating rangelands on a county-wide or state-wide basis. Grasshopper treatment programs, such as the Grasshopper Integrated Pest Management Program (GHIPM), across Great Plains region have been managed by federal agencies such as the U.S. Department of Agriculture's Animal and Plant Heath Inspection Service-Plant Protection and Quarantine. Elucidating the processes important to increases in grasshopper abundance at each of these scales would help to focus management efforts at each level and result in more effective cooperative treatment programs.

A prototype for such a management scheme was proposed by C.V. Riley and his colleagues in 1880 (USEC 1880) in a lengthy report on the Rocky Mountain Locust (Melanoplus spretus), a species which exhibited extremely large-scale habitat use. Their suggestion was to establish "a permanent system of observations and warnings" throughout the affected region, which could provide regular reports on "the situation and ex-
Locust would certainly have merited the establishment of such a system. The current losses caused by grasshoppers may not generate the same urgency for monitoring activities, but a coordinated system of regular surveys would be easily implemented. The APHIS surveys already canvass agricultural lands across seventeen western states and the National Agricultural Pest Information System (NAPIS) could serve as a central clearinghouse for the information gathered.

Because grasshopper surveys are conducted by individual offices in each of the seventeen western states, sampling methods differ. Standardization of sampling methods, frequency, and timing are necessary. Additionally, the current funding climate for grasshopper monitoring, management, and research casts doubt on the future of the surveys. Despite these obstacles, the benefits of coordinating annual grasshopper surveys across the Great Plains would far outweigh the costs. A single, very large scale data set would be created which would allow researchers to investigate grasshopper dynamics over a range of spatial and, as additional years of data are collected, temporal resolutions. Comparison of infested areas across habitat types and with non-infested areas during the same season would yield insights into the mechanisms which regulate population dynamics.

The use of scale-explicit models has already been adopted in many areas of ecology. As tools for handling and analyzing spatially-explicit data, such as geographic information systems (GIS), become more commonplace, models based on scale-defined levels of organization will become increasingly widespread. The incorporation of multivariate data into scalebased models promises to be useful in the study of grasshopper communities.

The future of grasshopper management rests on our understanding of this complex system. There is a need to generate new hypotheses and test them in the field, consider time lags in driving variables, and examine combinations of factors instead of looking for one-at-a-time correlations. Populationlevel studies of individual species, coupled with communitylevel studies, at multiple spatial and temporal scales are necessary to address the gaps in our knowledge. 
In a time of changing agricultural practices, reduced federal funding for control efforts, and uncertainty regarding the impacts of global temperature change, the need to understand the ecology of grasshoppers is likely to grow more urgent. While applied research may lead to improvements in grasshopper monitoring and control programs, in the end, our most important lesson is likely to be that which teaches us how to see grasshoppers not as a "foe" but as a natural part of agroecosystems.

\section{References}

Parker, J. R. 1937. The grasshopper problem in the United States, pp. 1-20. In: Proceedings, Fourth International Conference for Anti-Locust Research, April 1936, Cairo, Egypt. US Dep. Agric. Bureau of Entomology \& Plant Quarantine, Washington D.C.

Riley, C. V. 1877. The locust plague in the United States: being more particularly a treatise on the Rocky Mountain locust or socalled grasshopper, as it occurs east of the Rocky Mountains, with practical recommendations for its destruction. Rand, McNally \& Co., Chicago, Ill.
Schlebecker, J. T. 1953. Grasshoppers in American agricultural history. Agricultural History 27: 85-93.

[USEC] United States Entomological Commission. 1878. First annual report of the United States Entomological Commission for the year 1877 relating to the Rocky Mountain Locust. Government Printing Office, Washington, D.C.

[USEC] United States Entomological Commission. 1880. Second report of the United States Entomological Commission for the years 1878 and 1879, relating to the Rocky Mountain Locust and the Western Cricket. Government Printing Office, Washington, D.C.

[USEC] United States Entomological Commission. 1883. Third report of the United States Entomological Commission, relating to the Rocky Mountain Locust, the Western Cricket, the Army Worm, Canker Worms, and the Hessian Fly. Government Printing Office, Washington, D.C.

The author is with the Department of Rangeland Ecosystem Science, Colorado State University, Fort Collins, Colo. 80523

Current address: USDA-ARS Northern Plains Agricultural Research Laboratory, 1500 N. Central Ave., Sidney, MT 59270, (406) 482-9484, Fax: (406) 482-5038, E-mail: kskinner@ sidney.ars.usda.gov

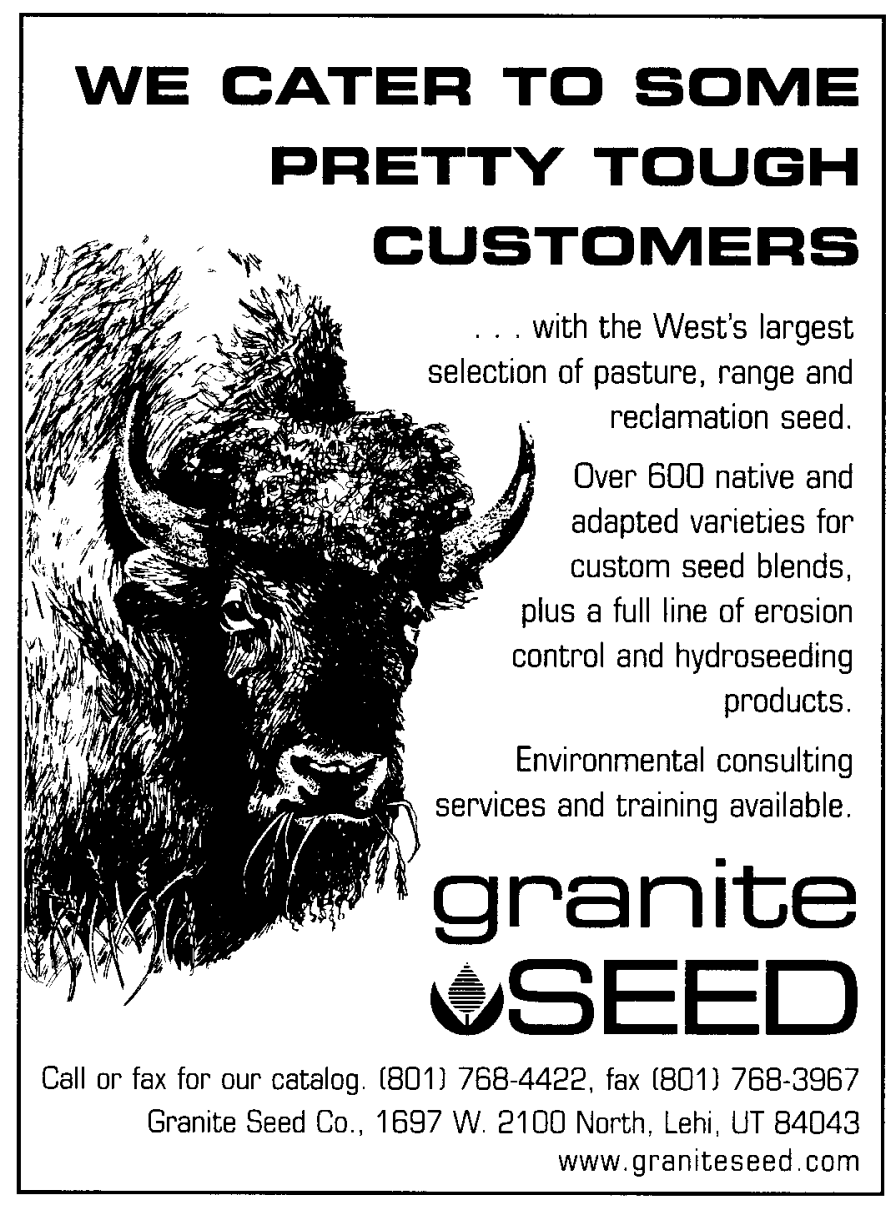

